\title{
Developing Students' Critical Thinking: A STEAM Project for Chemistry Learning
}

\author{
Yuli Rahmawati", Syauqi Faizka Ramadhani, Afrizal \\ Department of Chemistry Education, Faculty of Mathematics and Natural Sciences, Universitas Negeri Jakarta, Indonesia
}

Received September 20, 2019; Revised November 30, 2019; Accepted December 4, 2019

Copyright $\subseteq 2020$ by authors, all rights reserved. Authors agree that this article remains permanently open access under the terms of the Creative Commons Attribution License 4.0 International License

\begin{abstract}
The aim of this research was to develop students' critical thinking skills through a Science, Technology, Engineering, Arts, and Mathematics (STEAM) project in chemistry learning in thermochemistry topic. A qualitative research method was employed with interviews, observations, reflective journals, critical thinking tests, and student activity sheets as data collection tools. Forty secondary school students participated in the research using project based on learning consisting of six steps: Essential Questions, Project Planning, Schedule Compilation, Monitoring, Result Testing and Evaluation. The Miles and Huberman analysis technique, based on coding critical thinking, was used to analyze data. The five indicators of critical thinking skills identified by SCIT1020 (Power of Science and Technology), namely: Identify the Question at Issue, Conceptual Understanding, Ideas Connection, Assumptions and Inferences, the research found that the students' critical thinking skills were not significantly developed. Among the five critical thinking indicators, one specific skill found to be undeveloped was to identify the question at issue, meaning that the students were not able to formulate and identify questions relating to a problem or topic. This was due to the limited conceptual understanding of thermochemistry material. The students faced challenges in developing their critical thinking skills in relation to chemistry concepts. Critical thinking skills can help students navigate through their daily lives by applying what they learn at school to problems or issues that arise at home or in the community. The STEAM project involved making a steamship using thermochemistry, particularly heat, the enthalpy of standard combustion and enthalpy calculations. Methanol, ethanol and palm oils were the fuels used to move the steamships. In the project, students had to analyze which fuel caused their steamship to move the furthest.
\end{abstract}

Keywords STEAM, Project Based Learning, Critical Thinking, Thermochemistry

\section{Introduction}

Thinking skills are indispensable for helping to find solutions to life's challenges. These skills include critical thinking, creative thinking, and the ability to solve problem [1]. [2] defines critical thinking as identifying assumptions and various perspectives, and examining their validity so as to make decisions based on the information. Critical thinking is an important skill to enable students to address personal or social challenges and problems in their lives [1]. They require thinking skills to understand concepts and to verify assumptions and draw conclusions. A critical thinking process is not merely about making an argument and synthesizing information, it also demands that a person forms sensible arguments. [3] states that it is not enough for students to simply master critical thinking skills, but they also need to utilize these skills effectively. Critical thinking skills encourage students to think independently and solve problems at school and in the context of their daily lives [4]. Based on these assumptions, critical thinking skills are an important thing, but the reality on the ground is not as expected. Critical thinking skills of students in Indonesia are still relatively low. Large-scale international comparative studies such as Trends in International Mathematics and Science Studies (TIMSS) and the OECD's Program for International Student Assessment (PISA), show Indonesia ranked 64 out of 72 participating countries in the PISA assessment [5]. The international assessment results showed Indonesia students faced the challenges in dealing with critical thinking assessments, especially in science and mathematics.

Teaching and learning programs that overlook critical thinking skills affect students' ability to think critically [6]. The study of chemistry requires a combination of cognitive, affective and psychomotor activities that can help develop critical thinking habits [7]. One approach to developing students' critical thinking skills is through a STEAM 
(Science, Technology, Engineering, Arts and Mathematics) project approach. STEAM is a developing educational model that breaks down traditional academic subject 'silos' of science, technology, engineering, arts and mathematics and restructures them into an integrative curricula framework [8]. A STEAM approach could encourage students to develop their creativity and critical thinking skills more effectively than a traditional content delivery approach [9].

Previous research found that STEAM integrated learning would guide students to develop problem solving, critical thinking and collaborative skills [10]. This view is supported by [11] who states that while the intensification of STEAM integration might not be effective, well integrated instruction paves the way for students to learn from a more relevant and stimulating experience, encouraging the use of critical thinking skill on a higher level, thus increasing student retention.

STEAM also offers a number of learning process benefits, including allowing students to become independent and innovative learners, better at problem solving, inventive creative, logical thinkers and technology literates [12]. Previous studies found that integrating math and science offers positive impacts on student attitude and interest at school [13], their motivation to study [14] and achievement [15] as well as allow students to develop 21st century skills including critical thinking, creativity, communication and collaboration [16]. The majority STEAM studies have been conducted in several countries such as US, Taiwan, Turkey, etc., but limited study in Indonesia, especially in implementing in school environment. Therefore, this study will contribute to exploring the effects of STEAM in Indonesia, especially in chemistry learning

Learning chemistry is challenging due to the requirement that competence in basic concepts is essential. Chemistry is a difficult subject given that abstract concepts need to be understood, and because of its limited relationship to students' day-to-day lives [17]. Chemistry involves understanding macroscopic, microscopic and symbolic representations [18]. In order to develop a good understanding of chemistry concepts, all three representations are important within a chemistry lesson. Students are accustomed to memorizing facts, there by overlooking concepts. Chemistry is about the phenomenon and materialistic laws of nature, including composition, character and energy transformation that support material transformation. Chemistry is an essential field of knowledge in today's world, and yet students often face difficulty with the subject given that the chemistry curriculum consists of many abstract concepts and theories [17]. [19] and [20] reported that students prefer algorithmic studies and procedural knowledge compared to the conceptual study of chemistry.

The aim of this research was to develop students' critical thinking skills through a Science, Technology, Engineering, Arts, and Mathematics (STEAM) project in thermochemistry. Project-based learning is a student-centered pedagogy that involves a dynamic classroom approach whereby students acquire a deeper knowledge through active exploration of real-world challenges and problems [21]. Application of the STEAM approach also encourages students to understand each STEAM component in a chemistry study. Learning activities integrate each of the STEAM components; science explains the concept of thermochemistry, technology describes the use of the latest technology that enables students to implement the activities, engineering describes the techniques used by students during project completion, the arts engage students' creativity in project design, and mathematics determines the formulas students will use during the learning activities. The five disciplines are integrated to create project that applies chemistry to issues in everyday life. The project required students to create a steam-powered ship by implementing the concept of thermochemistry, particularly heat, the enthalpy of standard combustion and enthalpy calculations. Five ideal criteria were identified for creating the steamship: a front, a back, a chimney, a fuel tank, and a kiln. Methanol, ethanol, and palm oils were used as fuel to run the steamship and would determine whether or not it ran successfully.

\section{Methods}

The study employed a qualitative case study research design with data collected from interviews, observations, reflective journals, students' daily activities sheet and critical thinking test, critical thinking test questions based upon the critical thinking skills rubric of SCIT1020 (Power of Science and Technology, 2013). A project based on learning model divided into six steps was used to elicit the essential question, to plan the project, to list the schedule, to monitor the projected growth, to test the results and to evaluate the project. The steps of the project based on learning approach can be seen in Figure 1. 


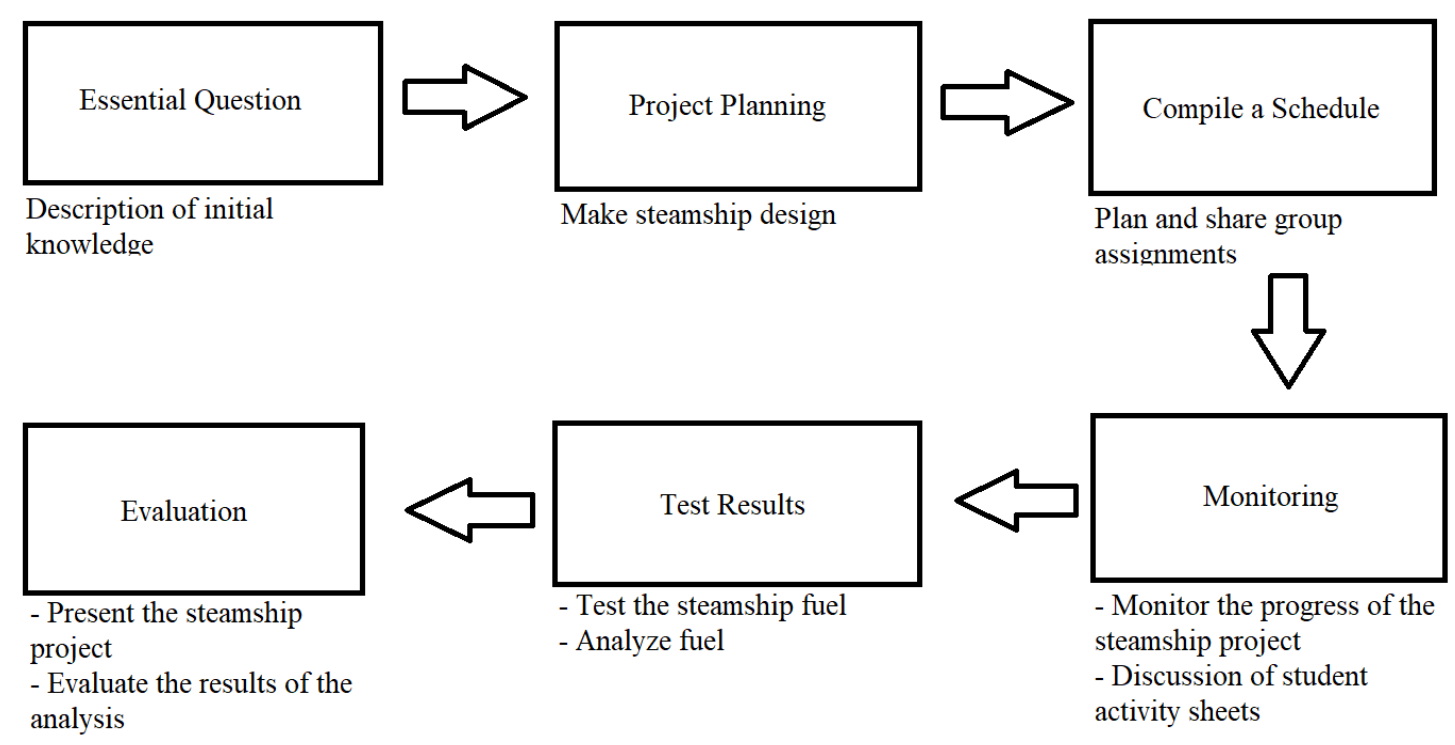

Figure 1. Steps for STEAM Project Based Learning

The STEAM project activity steps were carried out sequentially and repeatedly in each of ten lessons over a period of five weeks. The essential question was developed in regard to students' initial understanding of the thermochemistry concept. Project planning involved creating the steamship design and choosing materials. Organizing the project schedule is related to project planning and the division of tasks. Monitoring consisted of monitoring the progress of making the steamship and group discussions, while testing the results is related to fuel testing using ethanol, methanol and palm oil and evaluations consisting of presentation and analysis of the steamship project results.

The 2013 curriculum, with a chemistry allocation of 4 hours per week, is used in Indonesian school. The steamship project applied thermochemical concepts from the first semester XI grade material. The challenge was to relate the steamship project to thermochemistry, particularly to the sub-major concepts of heat, the enthalpy of standard combustion and enthalpy calculations. This study developed "Steamship STEAM project design" using the following design which has been adjusted to create the steamship project related to thermochemistry material.

The science principles in Figure 2 include the heat and enthalpy of standard combustion material. The technology component includes the selection of tools and materials and the engineering component addresses the working principles of a steamship. Art principles are incorporated in the steamship model design and Mathematics concepts are included in enthalpy calculations. As one of the success criteria, students were required to determine which fuel would allow the steamship to travel the furthest. Different fuels are tested to promote maximum movement for the steamship. In each process, teachers played an important role as facilitators while students worked collaboratively to complete the project. 


\section{Technology}

(Selection of Tools and Materials)

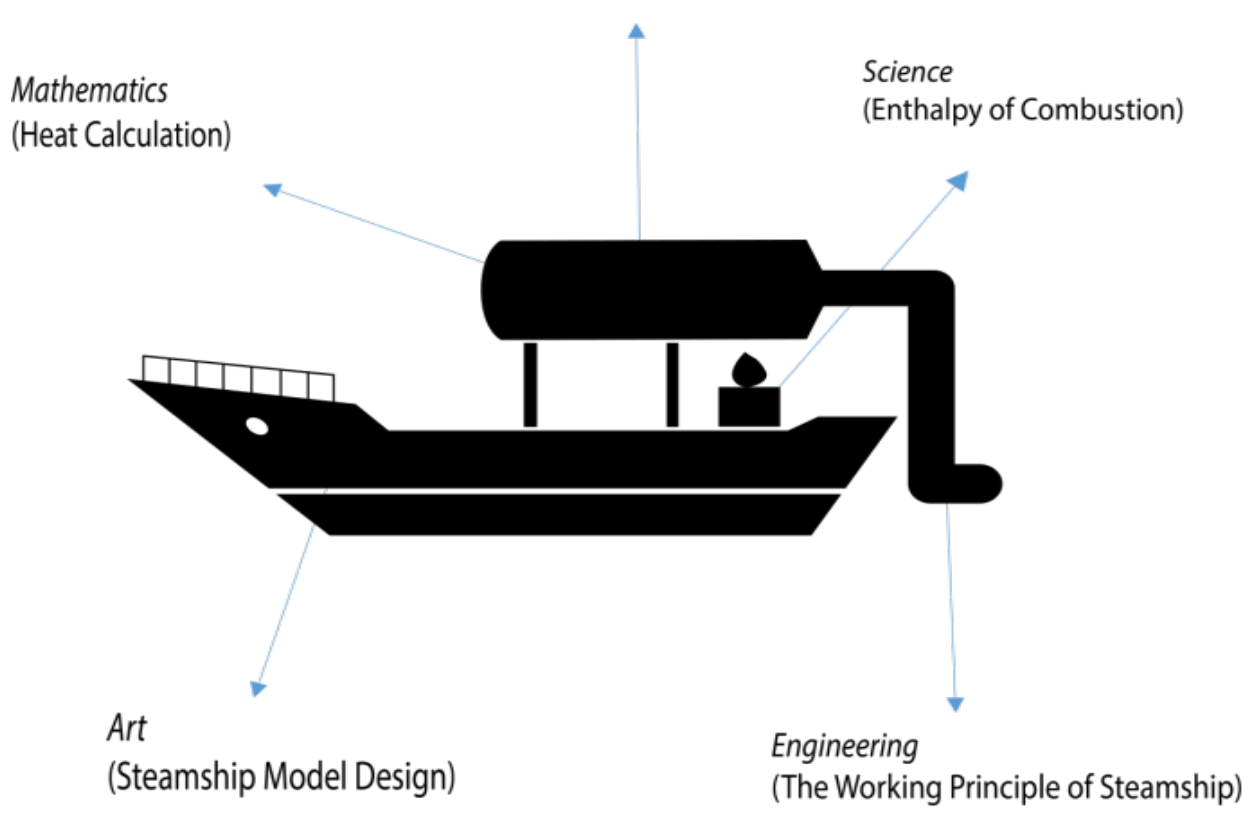

Figure 2. Steamship STEM Project Design

\subsection{The Participants}

The participants in this study were 40 grade XI science stream students at a senior high school in Jakarta, Indonesia. Of this number, 14 were males and 26 were females. Students' cognitive abilities in chemistry preparation varied from high to low.

\subsection{Data Analysis}

Data analysis was conducted by way of data reduction from interviews, observations, reflective journals, students' daily activities sheets and critical thinking test. The coding of data used in grouping was based on the components of critical thinking, 1) identify the question at issue, 2) conceptual understanding, 3) ideas connection, 4) assumptions and 5) inferences. The data were presented in narrative texts. The conclusions were then verified by checking their consistency and compatibility with other data collected. Quality standards used in this study are trustworthiness and credibility through prolonged engagement, persistent observation, progressive subjectivity, and member checking.

\section{Results and Discussion}

\subsection{STEAM Project for Learning Thermochemistry}

The project method using a STEAM approach aimed to develop students' critical thinking skills. The project began with the introduction of thermochemistry materials to the students. This initial knowledge about thermochemistry was useful as a supplement for students' initial knowledge of developing projects. After students were introduced to the thermochemical material, they were introduced to the concept of STEAM whereby, the teacher introduced Science, Technology, Engineering, Arts and Mathematics into the project. Science was related to the topic of thermochemistry. Technology meant the students had to use technology in making the steamship. Engineering meant the students had to know the working principles of a steamship. Art related to how the students designed the project and Mathematics related to the application of mathematical skills required for making the steamship.

The teacher introduced the steamship model, and the limitation of steamship fuels, and made connections to chemical concepts to improve the fluency of the students' thinking. As expressed by one student, "the teacher introduced the history of ship evolution in class. We found out that the ancient ships were mostly made of wood". The teacher then grouped the students and instructed them to divide the tasks among all group members to specify responsibilities, such as collecting and sorting out network information, collecting materials and producing design drawings, to help nurture the flexibility of their thinking. The project required the students to make a simple steamship in 6 groups of 6 or 7 students. The students began the project by developing a steamship design, they then determined what materials were required to build it and these details were recorded on an activity sheet. 

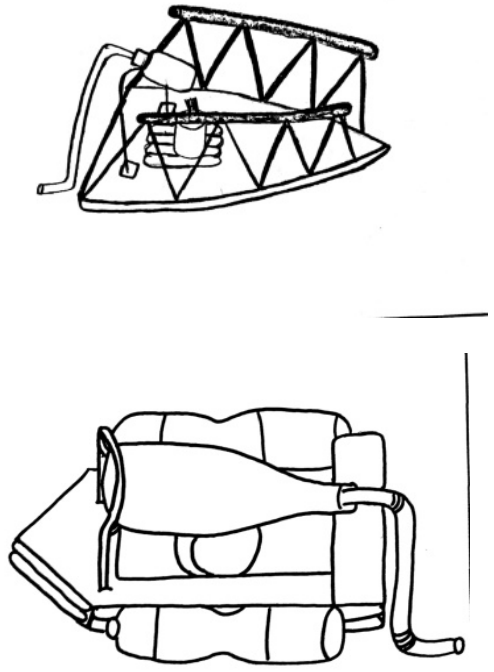

Figure 3. Students' Steamship Design

As demonstrated in Figure 3 above, each group created a different design made in accordance with the steamship criteria that required a front, a back, a fuel tank, a kiln and a chimney.

This activity challenged the students to be creative in determining the ideal material for designing a steamship. Designs needed to consider nonflammable materials, steamship principles and the buoyancy of lightweight materials. Students were asked for their opinion of the STEAM approach during the first lesson. One student responded as follows.

"Today is great day because my friends and I are making a Steamship that we have not done before"

(Student Reflective Journal, October 19, 2018)

The student's response indicates that they were motivated by the STEAM project because they had never participated in a project like this before. During the next step of the project, the students made the steamship according to their design, and as shown in Figure 4, several different design were created due to considerations being made such as ship weight and ship balance.

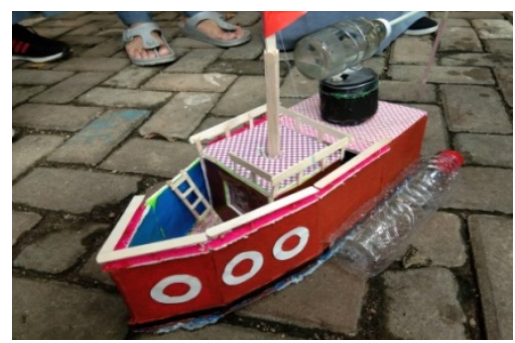

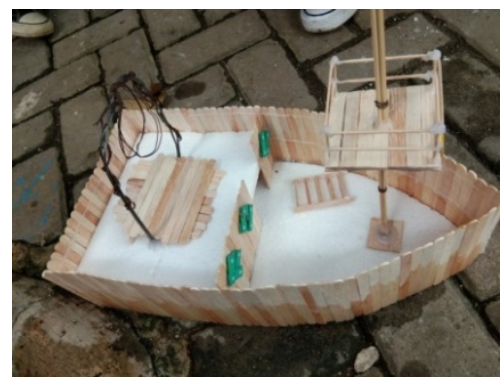

Figure 4. Students' Steamship

The Art discipline was visible in the model design of the ships as various colors were used to decorate them. Next, the steamship was tested and, based on observations of the 6 groups two groups failed, the case of two groups that failed in the steamship test was because the axis distance was so long that the incineration distance was too high which caused the ship to be unbalanced and sunk. The fuel test was completed over two lessons using methanol, ethanol, and palm oils. All three of these fuels were compared to determine which fuel caused the steamship to move furthest by using a heat calculation. The results of the fuel test result provided new information for the students as reported in the following statement.

\section{"We now the working mechanism of a steamship"}

(Student Reflective Journal, October 26, 2018)

After fuel testing was carried out, students were able to better understand the working principles of a steamship because the activity process showed how the mechanism of the ship ran with the help of steam produced from water boiled by the fuel.

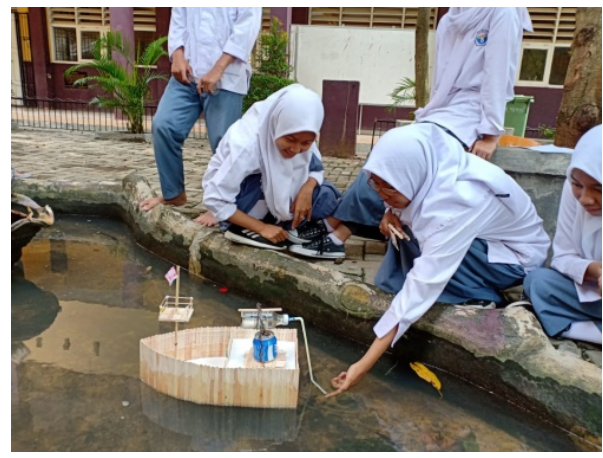

Figure 5. Students' Activities (fuel test)

Figure 5 shows fuel testing activities that went smoothly apart from some small obstacles such as the combustion bottle breaking and a leak in the chimney. However, each obstacle was overcome by every group. Each group had discussion questions to answer on an activity sheet as pictured in Figure 6. 


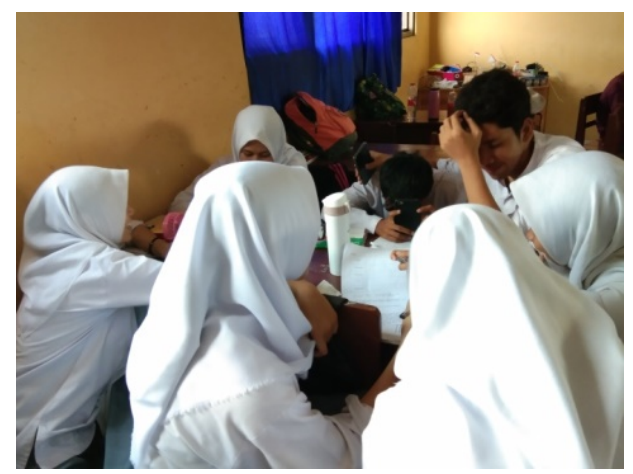

Figure 6. Group Discussion

Discussion sessions were developed as an evaluation of each group member's contribution during the STEAM project. Students were given the chance to present their analysis of the steamship project using PowerPoint and a poster which they presented to the other groups, as pictured in Figure 7 below. At this stage, the students played a leading role as, group by group, they presented their design ideas and applied STEAM related knowledge while sharing the problems they encountered during the process, as well as their solutions. This exercise allowed students to practice presenting their thoughts in words. As stated by one student, "It's not an easy task to clearly explain our thoughts and innovative design ideas in words" and, "I was really nervous when I gave the brief report on the platform for the first time. I made it thanks to my good preparation".

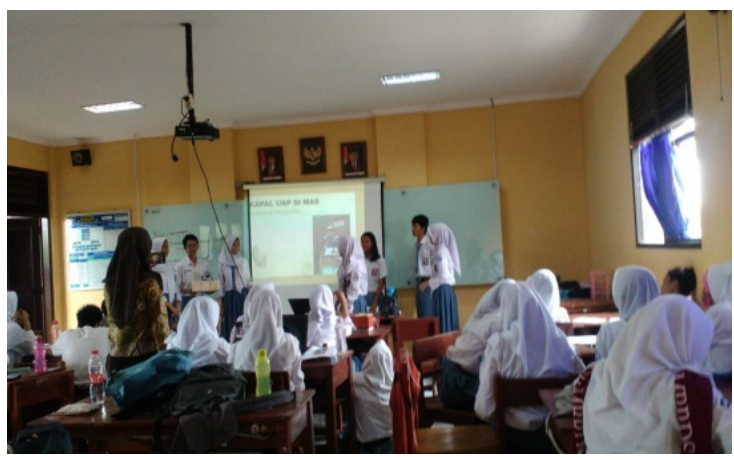

Figure 7. Group Presentation

Due to the choice of fuel contributing to the ability of the models to travel different distances, the results of each group differed. Each group came up with their own reasoning for the results of the test. These different perspectives strengthened the discussion and allowed the other groups to see why differences occurred. Students participated actively during the presentations as they enthused about the differences they discovered.

"I got some information about science through the STEAM project, I understand better how to make a steamship using a secondhand, know the working mechanism of the Steamship, and I am to be more creative and proficient in counting" (Student Interview,

\section{November 19, 2018)}

The statement above shows that a STEAM project can improve critical thinking and creativity of students because learning covers a variety of disciplines. Previous studies have also shown that STEAM projects can develop creativity, including adventurousness, curiosity, imagination and challenge [22]. For the teacher, the challenge of developing projects and linking them to the basic principles of STEAM encourages students to develop creativity and critical thinking [9].

\subsection{Student's Critical Thinking Ability in the Learning Process}

Critical thinking refers to an ability to analyse information, to determine the relevance of information gathered and to apply it in solving problems. The implications of learning via a STEAM project on students' critical thinking skills can be observed during the learning processes, discussing the problem and the results of the steamship experiment. The results of the critical thinking tests were validated expert lecturers, one in education, one materials expert and a chemicals expert.). Indicators of critical thinking skills observed were categorized as: Identify the Question at Issue, Conceptual Understanding, Ideas Connection, Assumptions, and Inferences (SCIT 1020 Rubrics for Critical Thinking / Analytical Question (Power of Science and Technology, 2013).

\subsubsection{Identifying the Question at Issue}

Question identification relates to a student's ability to formulate and identify questions regarding a problem or relating to a topic. A student is said to have qualified the question identification standard when she is able to formulate a question and when she actively asks questions. Critical thinking skills are included in the question identification criteria of problem setting. An example of questioning occurred during fuel tests where a student inquired, "Does the size of the ship affect its speed?" Another student asked, "Are there other types of fuel that can be used by the steamship?" Other student's questions included, "Can tissue be used as steamship axis?", "Does the diameter of the suction used affect the speed of the steamship?", and "Why does the use of oil fuel slow down the ship?" The STEAM based project encouraged students to ask questions and show their enthusiasm towards their learning, as supported by [23] who espouses that the characteristics of a student-centered STEAM approach encourage students to actively ask questions. Identify The Question at Issue means that students develop question when they are motivated to explore the steamship attributes and link them to thermochemistry concepts. By thinking critically students organize their knowledge and experience while exploring various context-related questions.

Only a few students were able to formulate and identify questions regarding to the problem or topic. This was due 
to the lack of understanding of the problem or topic which explains why critical thinking skill plays a significant role in understanding chemistry [24]. This result is also supported by [25] who noted that critical thinking is required by students in making reliable and responsible decisions, enquiring into issues, asking questions, deliver new answers, looking for information and drawing a conclusion.

Students' critical thinking skills can also be seen from the answers to the critical thinking test. The concept of critical thinking questions indicator identifies the question at issue discusses how students can predict the death of 7 young people in a home.

a) The following is one of the reactions that take place when the heating works. Complete the following reaction! $\mathrm{CH}_{4}(\mathrm{~g})+\ldots \ldots . . \ldots \ldots . .+2 \mathrm{H}_{2} \mathrm{O}(\mathrm{g})$

b) When the amount of oxygen is not enough, the methane oxidation reaction cannot fully run and the formation of $\mathrm{CO}(\mathrm{g})$ gas, this gas can poison people around the heater with a chimney if the concentration in the air exceeds a predetermined threshold value. In the information provided, explain the reason for the death of 7 young people! (There is a heater with a chimney in the house of seven young people).

Some students answered correctly about choice a. The following are the results of student interviews that incorrectly answered the question.

Teacher : Why did you answer the reaction with $\mathrm{CH}_{4}+\mathrm{CO}_{2} \rightarrow \mathrm{C}_{2}+2 \mathrm{H}_{2} \mathrm{O}$

Student : I still don't understand how to make the right reaction.

Teacher : Do you know that the question is an example of a combustion reaction?

Student : I don't know if it's a combustion reaction

Teacher : What do you know about the combustion reaction?

Student : A combustion reaction is a reaction that makes a substance damaged or lost.

(Student 21, Interview, 23 November 2018)

These results indicate that if students do not understand the concept of combustion reactions. Combustion in chemistry is materials that are often problematic, especially when oxidation and combustion are related to everyday life experiences. Daily life experiences are usually the main source of alternative explanations and conceptions among students [26]. Interpretations of everyday phenomena usually lead to alternative conceptions where students believe that all chemical reactions cannot be reversed, that combustion is usually associated with the destruction or loss of matter and mass or that combustion always produces gas compounds [27].

Only a few students could answer question $b$ accurately and in detail, as reflected in the example below:

"The heater uses methane fuel so that the combustion produces more carbon monoxide, the heater in the house seems to have a problem so that carbon monoxide enters the house and causes the amount of oxygen to be reduced so that 7 young people inhale it and die" (Student 10, Interview, November 23, 2018)

Few students were able to answer the question precisely and in detail while other students answered simply, "Because they breathed in carbon monoxide", without explaining the biology concept clearly. These results indicate if a student's critical thinking skills are not developed, this is because students have not been able to explain in detail the causes of death of these 7 people. The concept of this problem is related to daily life. [28] states contextual based teaching causes more student involvement in science concepts, one example of contextual based teaching is by applying the STEAM approach, this is because STEAM can be integrated into chemistry learning in real-life problems in the Indonesian context [10]. Therefore, school education must enable students to understand their daily lives, this is reinforced by [29] regarding science in everyday situations having the potential to make teaching more interesting and this will make most students more motivated to learn so students will better understand concepts.

\subsubsection{Conceptual Understanding}

Conceptual understanding is related to students' skill in analyzing an issue with the existing knowledge they possess. Critical thinking skills included in the criteria of conceptual understanding can be seen in the execution process of the steamship project as demonstrated below:

"When the teacher is presenting a video about a snowman which suddenly melts when exposed to the sun and asks why it happened? One student answered "Because the snowman absorbs the heat from the sun, making the snowman's temperature to drop and melt, where the process is called endotherm".

(Observer 2, Field Notes, 19 October 2018)

The statement depicts that the student used critical thinking skills about endotherm and provided a detailed explanation about the endotherm process that occurred to the snowman by learning through an integrated STEAM approach. The student actively builds their own knowledge through a fun learning experience [8].

Critical thinking skills were also analyzed during fuel tests. It was found that the majority of the students combined their initial concept understanding with thermochemistry concepts during the STEAM learning process.

"Burning will create heat, so we have to avoid the use of Styrofoam because it would melt when it is exposed to heat (heat energy and heat transportation)."

(Student no.6, Reflective Journal, 2 November 2018)

"The process of heating water and choosing fuel is very important to create steam. Action and reaction force could be implemented as the work principle of steamers 
(Newton's III Law)."

(Student no. 10, Reflective Journal, 2 November 2018)

These sample journal entries show that some students were able to understand the thermochemistry concepts, especially heat and burning enthalpy, and were able to link them to the principle of a working steamship. Results showed that students were able to develop their critical thinking, an outcome that is supported by a study conducted by [9] who stated that the challenges of developing a project and relating it with basic STEAM principles encouraged students to develop their creativity and critical thinking.

Students' critical thinking skills were also noted in the answers to the critical thinking test, as noted below. The concept of a critical thinking questions indicator of conceptual understanding related to the determination of systems and the environment.

"Chemical reactions (ammonium chloride and barium hydroxide) here as a system and beaker as environment".

(Student 6, Interview, November 23, 2018)

The answers above show that if all students are able to determine which systems and environments are included, then understanding of the concept of systems and environments has been well mastered by students, [30] researchers also showed the same results wherein their studies, $22 \%$ (of $n=207$ ) correctly identified the chemical reaction as a system while only $6 \%$ correctly identified the environment.

\subsubsection{Ideas Connection}

Connection of ideas is related to students' skills in analyzing, organizing, and connecting various ideas or in this research connecting disciplines to be integrated within a STEAM context. Critical thinking skills included in the connection of ideas criteria can be found in the execution phase of the steamship project. The example below was taken during an activity sheet discussion about the working principles of a steamship.

"The working principle of a steamship uses the thermodynamic concept. If something is warmed up, it is going to change to be the energy. The heat sources from the fuel are then warmed up in a tank with a burner and on it there is a glass bottle filled with the water. If the water has boiled there is going to be a change in energy arisen the steam, namely the heat energy. It made the steamship to move".

(Group 1, Activity Sheet, November 16, 2018)

"The working principle of as Steamship is based on the law of action-reaction (Newton law II). The steamship uses a Newton law III as well. Its machine gives an action style through a gas burst out of the back, and it gives a reaction style through an impetus steam. This movement is called the convection".

(Group 4, Activity Sheet, November 16, 2018)
The answers above, show that the students understood the principle of steamships and some groups did not only identify the chemical principles but also other disciplines such as physics (Newton Law). In the connection of ideas, students were trained to think critically in connecting various ideas and concepts, in this case developing the working principle of steamships and connecting to other disciplines. The concept might include significant related information or is connected to other concepts [31]. This means that no concept stands alone, but is connected to other concepts, so in order to learn a certain concept each person must be able to differentiate that particular concept to the others.

The example show that the students' skills of connecting ideas have developed through the research process. This result is supported [32] who stated that a STEAM approach encourages students to connect various ideas and that it is highly related to conceptual understanding [33]. Mastery of one discipline would allow students to be able to connect knowledge to other disciplines, such as chemistry and physics.

Students' critical thinking skills can also be seen from answers to the critical thinking test. The concept of critical thinking questions indicator, Ideas Connection relate to instant cold and hot packs that are used as a tool to reduce cold or hot temperatures. Students were required to find information on the compounds used and how the compounds work. One student answered as follows:

"Hot pack, there are ammonium nitrate crystals and water bags while cold packs have magnesium sulfate crystals and water bags. If the packaging is squeezed the water bag will break and the crystals dissolve in water and temperature changes occur."

(Student 14, Critical Thinking Test Results)

"Cold packs, usually the compounds contained in cold packs are ammonium nitrate and water. The way it works is ammonium nitrate dissolves in water and the chemicals absorb heat and make the water cool while in hot packs, the compounds are calcium chloride. How it works is that calcium reacts with water and produces heat."

(Student 18, Critical Thinking Test Results)

These results indicate the skill of conceptualizing students' ideas has developed because some students can find compounds that can produce heat/cold.

\subsubsection{Assumptions}

Assumptions are related to students' skills in developing and presenting consistent assumptions. Students' critical thinking skills in making assumptions can be seen in the execution process of the steamship project. One example occurs during fuel tests, in which the fuel that propelled the steamship furthest was different for each group.

"Ethano fuel, because the fire produced is big so that the water quickly boils and out a lot of steam, and finally the Steamship moves quickly" 
(Student Reflective Journal, November 5, 2018)

"Methanol is the reason why a Steamship moves fast

because its combustion process is fast and big"

(Student Reflective Journal, November 5, 2018)

The answers above show that students were able to assume what type of fuel would cause the ship to move fast. The example below occurred during selection of material to make the steamship.

Teacher : Did you use the right material for your steamship?

Student : Not yet, because the bottle we used as a fire place often cracked.

Teacher : What do you think caused the crack?

Student : Maybe because the bottle we used is a drink bottle so it doesn't hold heat and also the bottle was cold so when it was heated the temperature changed rapidly and made the bottle crack.

Teacher : What did you do to solve the problem?

Student : Replace it with a dark bottle and a bottle at room temperature (not cold). Dark colored bottles seem to be more heat resistant than the ones that are clear that we used before.

(Student Interview, October 26, 2018)

Based on students' comments regarding their steamship, it appears that the students had developed their own opinions. There were students who said their steamship was good because they used suitable materials. There were also students who said their steamship was not good because they didn't use the right materials. These answers show that the students were able to think critically because they were able to make assumptions about their steamships and they could solve the problems that occurred and implement solutions to increase the performance of their steamship. This approach is supported by [34] who stated that STEAM integration could be implemented to develop critical thinking, communication, motivation, creativity, respect, discipline, collaboration, responsibility, adaptation and leadership as well as information and media literacy.

Students' critical thinking skills can also be seen from the answers to the critical thinking test. The concept of critical thinking questions indicators. Assumptions refers to statements related to sweating lowering the body temperature when rises where students must know what causes body temperature to rise as well as how body processes can lower body temperature. This indicator connects the concept of chemistry to everyday life as demonstrated below.

"When the human body carries out activities, there will be a combustion process in the body to produce energy which causes the body's temperature to rise when the body experiences an increase in temperature, so humans release body steam in the form of sweat to maintain a stable body temperature".

(Student 36, Critical Thinking Test Results)

In this response, the student has demonstrated that if the critical thinking skills developed, it is because students have understood the concepts of exothermic and endothermic and can connect the chemistry to events in everyday life.

\subsubsection{Inferences}

Drawing a conclusion is described as the ability to make a decision or draw a conclusion based upon adequate evidence. Some students discussed the result of each fuel used and compared them.

"The results of our group are that the steamship went a long distance using fuel methanol> ethanol> palm oil, this result is different from the heat calculation, because combustion that occurs in oil is incomplete combustion that causes the heat to be low, resulting in the distance travelled by steamship to be short".

(Group 4, Student Activity Sheet, November 5, 2018).

"The results of our group are the steamship ran far using methanol> palm oil $>$ ethanol, this result is different from the heat calculation, because the concentration of oil (oleic acid) of $43 \%$ and other substances while the concentration of methanol was 93\%. Therefore, methanol produced more heat than palm oil and runs faster".

(Group 6, Student Activity Sheet, November 5, 2018).

These answers indicate that students were able to deduce what fuel would cause the steamship to travel farther and provide a reason. Exploration of new knowledge, in this case about a steamship will develop students initiative to engage in chemistry learning [35]. The difference in the answers could be seen in the above statements, and this gave the students to opportunity to express their opinion based upon their learning experience [16]. The above results show that the students were able to come to a conclusion related to the steamship project, which is one criteria of critical thinking. This result is supported by [36] who stated that it is critical thinking that allows students to analyze their own thinking to ensure that they have come to a reasonable decision and an intelligent conclusion.

Students' critical thinking skills can also be seen from the answers to the critical thinking test, the concept of critical thinking problem indicator. Inferences, in Figure 8 are the enthalpy calculation. Understanding the concept of the enthalpy of formation and combustion reactions is needed to answer this problem, to calculate the enthalpy change the enthalpy formation value of each compound contained in the combustion reaction.

Test results showed that most students correctly answered questions about enthalpy calculations. Critical thinking skills had been developed because students could make combustion reactions correctly so that the enthalpy calculation results were correct. The development of critical thinking skills is because the chemistry learning process often prioritizes calculations rather than concepts. Many teachers believe that solving problems with numerical calculations will improve conceptual 
understanding as seen from the many calculation questions in the exam [37].

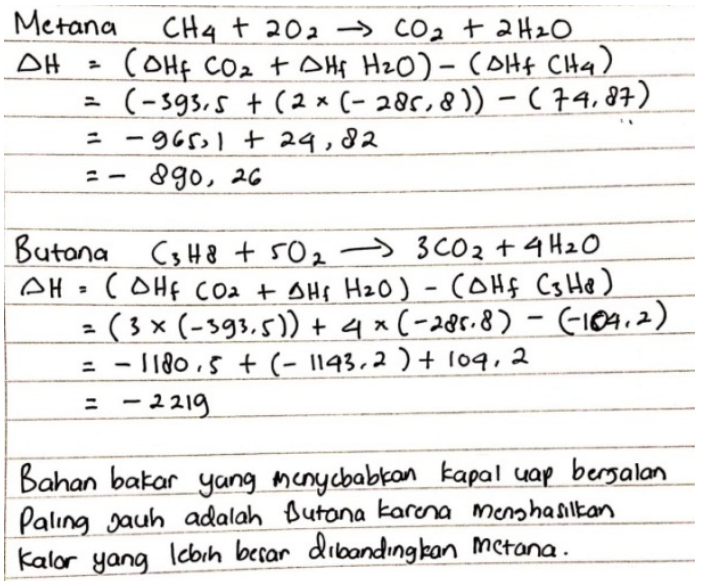

Figure 8. Enthalpy Calculation Result Test

\section{Conclusions}

The implementation of the STEAM project was accomplished through six learning steps: 1) the essential question step which could develop the ability to deliver a simple explanation; 2) the project planning step which could develop the aspect of building basic skills; 3 ) the schedule compilation step which could develop the aspect of strategy and tactics formulation; 4) the monitoring step which could develop the aspect of simple and strategized explanation delivery; 5) the result testing step which could develop the aspect of considering further explanations; and 6) the evaluation step which could develop the aspect of drawing a conclusion.

According to the result of the research and consequent discussion it can be concluded that the students' critical thinking skills regarding thermochemistry material were not developed. This can be seen that from five of the critical thinking indicators, one of the students' critical thinking indicators, Identify the Question at Issue was not developed. This result indicates that the students were not able to formulate and identify the questions related to the problem or topic due to the lack of understanding of thermochemistry material. Therefore, in order to increase students' critical thinking skills a continuous practice of the STEAM approach in schools is needed. The development of a strong STEAM program from early childhood, through to tertiary level is also important in order to create a society that is scientifically literate, able to think critically, and who understands the value of STEAM for the future of the planet [38].

\section{REFERENCES}

[1] F. Kalelioğlu and Y. Gülbahar, "The effect of instructional techniques on critical thinking and critical thinking dispositions in online discussion," Educ. Technol. Soc., vol. 17, no. 1, pp. 248-258, 2013.

[2] S. Brookfield, "Teaching for Critical Thinking," Int. J. Adult Vocat. Educ. Technol., vol. 4, no. 1, pp. 1-15, 2013.

[3] K. Holma, "The Critical Spirit: Emotional and Moral Dimensions Critical Thinking," Stud. i Pædagogisk Filos., vol. 4, no. 1, p. 17, 2016.

[4] S. M. Jacob, "Mathematical achievement and critical thinking skills in asynchronous discussion forums," Procedia - Soc. Behav. Sci., vol. 31, no. 2011, pp. 800-804, 2012.

[5] I. Indonesia, U. Nation, S. D. Goals, S. Indonesia, and V. Nam, “C oecd 2016,” pp. 1-8, 2016.

[6] G. Wells, "Lesson Plans and Situated Learning-and-Teaching (Suchman book review)," J. Learn. Sci., vol. 12, no. 2, pp. 265-272, 2003.

[7] K. P. Acharya, "Exploring Critical Thinking for Secondary Level Students in Chemistry: From Insight To Practice,” J. Adv. Coll. Eng. Manag., vol. 3, p. 31, 2018.

[8] G. Yakman and H. Lee, "Exploring the Exemplary STEAM Education in the U.S. as a Practical Educational Framework for Korea," J. Korean Assoc. Sci. Educ., vol. 32, no. 6, pp. 1072-1086, 2015.

[9] J. Larmer and J. R. Mergendoller, "Seven Essentials for Project-Based Learning," Educ. Leadersh., vol. 68, no. 1, p. 34, 2010.

[10] Y. Rahmawati, A. Ridwan, T. Hadinugrahaningsih, and Soeprijanto, "Developing critical and creative thinking skills through STEAM integration in chemistry learning," J. Phys. Conf. Ser., vol. 1156, no. 1, 2019.

[11] M. Stohlmann, T. Moore, and G. Roehrig, "Considerations for Teaching Integrated STEM Education," J. Pre-College Eng. Educ. Res., vol. 2, no. 1, pp. 28-34, 2012.

[12] J. S. Morrison, "Attributes of STEM education: the students, the academy, the classroom," TIES STEM Educ. Monogr. Ser., 2006.

[13] D. Bragaw, K. A. Bragaw, and E. Smith, "Back to the Future: Toward Curriculum Integration," Middle Sch. J., vol. 27, no. 2, pp. 39-46, 2015.

[14] J. T. Guthrie, A. Wigfield, and C. VonSecker, "Effects of integrated instruction on motivation and strategy use in reading," J. Educ. Psychol., vol. 92, no. 2, pp. 331-341, 2000.

[15] M. M. Hurley, "Reviewing Integrated Science and Mathematics: The Search for Evidence and Definitions from New Perspectives," Sch. Sci. Math., vol. 101, no. 5, pp. 259-268, 2010.

[16] S. Blackley, Y. Rahmawati, E. Fitriani, R. Sheffield, and R. Koul, "Using a makerspace approach to engage Indonesian primary students with STEM," Issues Educ. Res., vol. 28, no. 1, pp. 18-42, 2018.

[17] G. Sirhan, "Learning Difficulties in Chemistry: An Overview," J. Turkish Sci. Educ., vol. 4, no. 2, pp. 2-20, 2007. 
[18] D. F. Treagust, G. Chittleborough, and T. L. Mamiala, "The role of submicroscopic and symbolic representations in chemical explanations,” Int. J. Sci. Educ., vol. 25, no. 11, pp. 1353-1368, 2003.

[19] K. S. Taber, "Challenging Misconceptions in the Chemistry Classroom: Resources to Support Teachers," J. Educ., vol. 4, pp. 13-20, 2009.

[20] K. Scalise, J. Claesgens, M. Wilson, and A. Stacy, "Contrasting the expectations for student understanding of chemistry with levels achieved: A brief case-study of student nurses," Chem. Educ. Res. Pract., vol. 7, no. 3, pp. 170-184, 2006.

[21] N. V. Vargas, J. Luis, A. Ortiz, V. Manuel, and A. Ceballo, "Project Based Learning in the Technical and Vocational Education and Training," vol. 13, no. 9, pp. 767-776, 2018.

[22] S. J. Lou, Y. C. Chou, R. C. Shih, and C. C. Chung, "A study of creativity in $\mathrm{CaC} 2$ steamship-derived STEM project-based learning," Eurasia J. Math. Sci. Technol. Educ., vol. 13, no. 6, pp. 2387-2404, 2017.

[23] R. Long and S. Davis, "Using STEAM to Increase Engagement and Literacy Across Disciplines," Steam, vol. 3 , no. 1, pp. 1-11, 2018.

[24] M. Chandrasegaran, A.L., Treagust, D.F., \& Mocerino, “Thr Develovment Of Two-Tier Multiple-Chois Instrument For Evaluating Secondary School Students' Ability To Describe And Explain Chemical Reaction Using Multivel Levels of Refresentation.," vol. 8, no. 3, pp. 293-307, 2007.

[25] C. P. Dwyer and C. P. Dwyer, “An Introduction to Critical Thinking," Crit. Think., pp. 1-6, 2017.

[26] I. Eilks, J. Moellering, and N. Valanides, "Seventh-grade students' understanding of chemical reactions: Reflections from an action research interview study," Eurasia J. Math. Sci. Technol. Educ., vol. 3, no. 4, pp. 271-286, 2007.

[27] M. B. Nakhleh, "Why some students don't learn chemistry: Chemical misconceptions," J. Chem. Educ., vol. 69, no. 3, p. 191, 2009.

[28] P. J. Fensham, "Real world contexts in PISA science: Implications for context-based science education," J. Res. Sci. Teach., vol. 46, no. 8, pp. 884-896, 2009.

[29] J. Kortland, “ChemCom, PLON, Salter's Science, Chemie im Kontext," pp. 1995-1997, 2004.

[30] T. J. Greenbowe and D. E. Meltzer, "Student learning of thermochemical concepts in the context of solution calorimetry,” Int. J. Sci. Educ., vol. 25, no. 7, pp. 779-800, 2003.

[31] A. Ata Aktürk and H. Ö. Demircan, "A Review of Studies on STEM and STEAM Education in Early Childhood," Ahi Evran Üniversitesi Kırşehir Eğitim Fakültesi Derg., vol. 18, no. 2, pp. 757-776, 2017.

[32] A. W. Glancy and T. J. Moore, "Theoretical Foundations for Effective STEM Learning Environments," Eng. Educ. Work. Pap., vol. 1, no. 1, pp. 1-24, 2013.

[33] C. Mcdonald, "STEM Education: A review of the contribution of the disciplines of science, technology, engineering and mathematics," Sci. Educ. Int., vol. 27, no. 4, pp. 530-569, 2016.
[34] T. Hadinugrahaningsih, Y. Rahmawati, and A. Ridwan, "Developing 21st century skills in chemistry classrooms: Opportunities and challenges of STEAM integration," AIP Conf. Proc., vol. 1868, no. August, 2017.

[35] Y. Rahmawati and A. Ridwan, "Should we learn culture in chemistry classroom? Integration ethnochemistry in culturally responsive teaching Should We Learn Culture in Chemistry Classroom? Integration Ethnochemistry in Culturally Responsive Teaching," vol. 030009, no. August, 2017.

[36] K. Changwong, A. Sukkamart, and B. Sisan, "Critical thinking skill development: Analysis of a new learning management model for Thai high schools," J. Int. Stud., vol. 11 , no. 2 , pp. 37-48, 2018.

[37] E. Gaigher, J. M. Rogan, and M. W. H. Braun, "Exploring the development of conceptual understanding through structured problem-solving in physics," Int. J. Sci. Educ. vol. 29, no. 9, pp. 1089-1110, 2007.

[38] R. Sheffield, R. Koul, S. Blackley, E. Fitriani, Y. Rahmawati, and D. Resek, "Transnational examination of STEM education,” Int. J. Innov. Sci. Math. Educ., vol. 26, no. 8, pp. 67-80, 2018. 